\title{
Infection Control in Prosthodontics
}

\author{
J isa Ann Alex ${ }^{1}$, Sudhir N², Taruna $\mathrm{M}^{3}$, Ramu Reddy ${ }^{4}$
}

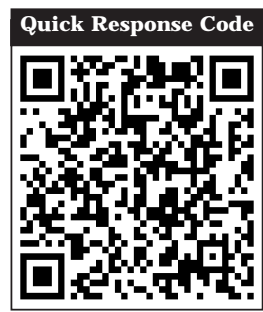

doi: 10.5866/2016.8.10041

1Post graduate

2Sudhir N

${ }^{3}$ Taruna $\mathrm{M}$

${ }^{4}$ Ramu Reddy

Department of Prosthodontics,

Kamineni Institute of Dental Sciences

Narketpally, Nalgonda, Telangana state.

\section{Article Info:}

Received: J anuary 9, 2016

Review Completed: February 10, 2016

Accepted: March 12, 2016

Available Online: May, 2016 (www.nacd.in)

(C) NAD, 2016 - All rights reserved

Email for correspondence:

jisaannalex@gmail.com

\section{Introduction:}

Dentistry is a field that involves the clinician and the patient being exposed to saliva and other infectious material. Prosthodontic patients are generally a high risk group relative to their potiential to transmit infectious diseases as well as acquire them. Ther efore recently, an increase in the awareness of the need for cross-infection control measures to protect against possible routes of transmission has been discussed. In a country like India, high on disease incidence and sterilization protocol need to be implemented on the highest priority. The prosthodontists are at an added risk of transmission because of the infection spreading through the contaminated lab equipments while working in the lab. Therefore infection control is an important concept in the present day dentistry

\begin{abstract}
:
Infection control is as old as disease control in health care modalities. The dental profession is at high risk due to the potential for disease transmission in dental dinic and dental laboratory. To avoid such transmission of the diseases, it is important to understand the mechanism of transmission of infection, pathogens involved and the safety measures that can be undertaken. This review insights the procedures to be followed in the clinic as well as thelaboratory in order to prevent the cross contamination.
\end{abstract}

Key words: Infection control, dental clinic, dental laboratory, disinfection, sterilization, transmission which has be followed in the clinics as well as in the laboratory. This article gives an overview of the possible risk of disease transmission and the ways to control them through effective sterilization and disinfection protocols.

\section{Transmission of diseases:}

Micro-organisms capable of causing disease are present in human blood. Contact with blood or saliva mixed with blood may transmit pathogenic microorganisms. ${ }^{1}$ The pathogens may be transmitted among the patient, dentist, dental care worker and the lab technician. Disease transfer to the dentist and dental staff during dental care is considered an " occupational exposure" to a given pathogen on the other side the disease may al so be transmitted from the dentist to the patient as well as from one patient to the other. ${ }^{2}$ The disease transfer from one patient 
to another in the dental clinics is considered as " cross infection". I nfection control is aimed to prevent such type of transmissions in the dental office. ${ }^{3}$

The dental professional must assume that every patient treated is a risk of cross infection and to adopt appropriate control measure. The cycle of cross contamination is demonstrated in Figure $1 .{ }^{4}$

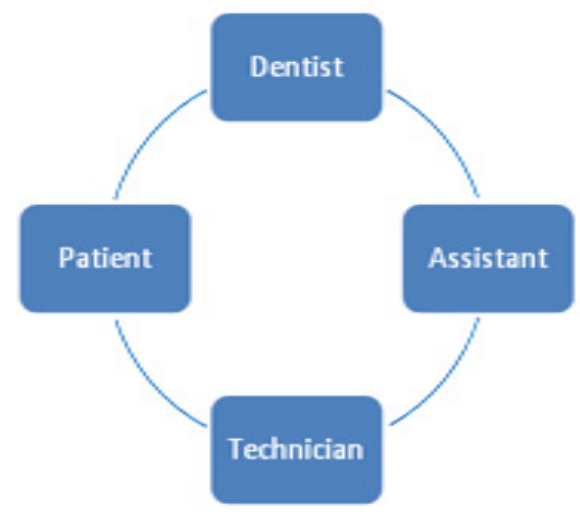

Figure 1: Cycle of cross contamination

\section{Organisms can be transmitted in dental settings through:}

1) Direct contact with blood, oral fluids, or other patient materials

2) Indirect contact with contaminated objects

3) Contact of conjuctival, nasal, or oral mucosa with droplets

4) Inhalation of airborne micro organisms that can remain suspended in the air for long periods.

Based on the article in DCNA 1996, 5 classes of risk have been described based on the level of risk and case of prevention. ${ }^{5}$

\begin{tabular}{|c|c|}
\hline Class Diserseses & Prevention \\
\hline 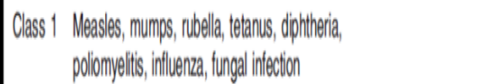 & Vacines avalaldele Risck minmal \\
\hline 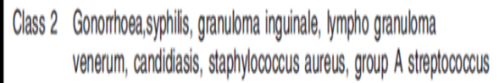 & $\begin{array}{l}\text { No vacinnesbiut treatment is } \\
\text { avaladaleRisk more than class } 1\end{array}$ \\
\hline Class 3 Varicella, herpes simplex, cylomengalo virus, EBV & High rate of prevalenneatroutlesome clinically \\
\hline Class 4 HBV, HCV, HDV, HNV & 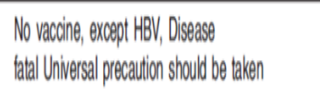 \\
\hline Class 5 TB & $\begin{array}{l}\text { Vacine not 100\% effectrveAir bome transmilssion } \\
\text { Hignest risk Respirataby precautions }\end{array}$ \\
\hline
\end{tabular}

\section{Infection control:}

There are some procedures in infection control which areto be followed strictly to prevent any cross contamination. The main emphasis should not be only on patient protection but also on protection of the dental team.

\section{The procedures involve:}

1. Patient screening

2. Personal hygiene

3. Personal protection

4. Instrument processing

5. Surface asepsis

6. Patient treatment

7. Laboratory disinfection

\section{Patient screening:}

Any treatment has to be performed only after a comprehensive patient evaluation. This is generally accomplished by recording medical history specially designed to identify the patients who are either particularly susceptible to infection or who are at risk of transmitting infection, known as carriers of disease or by being in a high-risk category. ${ }^{6}$

\section{Personal hygiene:}

Thorough forearm and hand washing is mandatory before and after treatment. Fingernails are kept clean and short to prevent perforation of gloves and accumulation of debris. Fingernail polish is not worn. Use surgical head cap, face mask and eye protecting glasses and long sleeved clinical coats. ${ }^{7}$

\section{Personal protection:}

Residents are required to have current immunizations against communicable diseases including hepatitis $B .{ }^{3}$ The vaccination programme must certainly be consi dered the most effective cross infection control measureto protect dental personnel and in turn their patients from a potentially fatal disease. ${ }^{8}$ In june 1982, council on dental therapeutics adopted a resolution recommending that all dental personnel having patient contact including dentists, dental students and dental auxillary personnel , and all dental laboratory personnel receive the hepatitis B vaccine. ${ }^{9}$

Dental clinic personnel should wear appropriate protective barrier such as eye wear or chin length face shields, disposable gloves, disposable masks , 
protective garments, and other needed items when performing procedures capable of causing splash or spatter of blood or other potentially infectious materials. ${ }^{10}$

Disposable gloves are single-patient-use items. The type of the gloves is chosen based on the procedure being performed. Latex exam gloves are adequate for most dental procedures unless a sterile field requires the use of sterile gloves. ${ }^{10}$ The use of powder free gloves will minimize the risk of and alleviate the symptoms of latex allergy. If the dental care provider, dental staff or patient is allergic to latex, alternatives such as neoprene or nitrile gl oves must be used. Utility gloves that are chemical and puncture resistant must be used when handling contaminated instruments, when performing operatory clean up, and for other contact with contaminated surfaces or disinfectant chemicals.

Masks are worn in the patient treatment area and when the dentist is manipulating the prostheses in the laboratory. The masks used should have at least $95 \%$ filtration rate of particles 3 to 5 microns in diameter.

Dental care providers and dental staff must wear protective eyeware which must be optically clear, antifog, distortion free, close fitting and shielded at the sides.

The level of protection from protective garments like long sleeves, closed neck, garment length, etc is determined by the procedure that is being performed. Generally cotton/polyester type fabric garments are also acceptable.

\section{Instrument processing:}

- Presoaking and cleaning

- Packing

- Sterilization

\section{Precleaning and cleaning solutions ${ }^{7}$}

Enzymatic solutions Removes blood and other proteinaceous material

Non-enzymatic Removes non-specific debris solutions

Mechanical cleaners Washers/disinfectors or ultrasonic cleaners

Rust inhibitors Retards corrosion of carbon steel

\section{Sterilizers}

Steam autoclave

Uses steam under pressure to sterilize $250 \mathrm{~F}$ to $273 \mathrm{~F}$ ( time varies depending on size of load and autoclave)Good penetration of heat into packages causes corrosionRequires drying time

Oven type dry heat sterilizer

Rapid heat transfer type dry heat sterilizer

Unsaturated chemical vapor sterilizer

Uses dry heat at 320F for 1-2 hrNo corrosion

U ses circulated dry heat $375 \mathrm{~F}$ for 6-20 mins

Uses unsaturated chemical vapor from formaldehydeand alcohol 273F for 20 mins

\section{Surface Asepsis: ${ }^{3}$}

There are two general approaches to surface asepsis

- $\quad$ Clean and disinfect contaminated surface

- $\quad$ Prevent surface from becoming contaminated by use of surface covers

- A combination of both may also be used

According to Miller and Palenik in 1994 chemicals used for surface and equipment asepsis are

- Chlorine e.g. sodium hypochlorite

- Phenolic compounds -
(a) water based
water with ortho- phenyl phenol or tertiary amylphenol or O benzyl- p-chlorophenol
(b) alcohol based - Ethyl or iso propyl alocohol with $\mathrm{O}$ phenyl phenol or tertiary amylphenol
(c) I odophor
- butoxypoly propoxy poly ethoxy ethanol iodine complex

\section{Patient Treatment:}

The responsibility for infection control procedures during patient treatment rests primarily on the dentist's ability to adhere to strict sterilization, disinfection and barrier techniques. The use of strict system of zoning in the clinic will 
reduce the number of areas contaminated and there by maintain asepsis.

The working area is sprayed and left for $10 \mathrm{mins}$ before any procedure starts along with the wiping of the operatory and chair with a disinfectant solution. The chair is covered with a disposable plastic sheath which has to be removed subsequent tothe treatment. All the patients are advised to rinse with chlorhexidine gluconate $0.12 \%$ and wear protective eye wear before the commencement of the treatment. ${ }^{11}$

The operator should wash the hands with antimicrobial cleanser before gloving and should only touch the patient and the disinfected area once gloved. A unit dose concept may be adopted for use in the clinic as a cross-contamination control measure. This may be applied to many items and materials in prosthodontics, such as impression materials and waxes. The materials should be dispensed by a noncontaminated assistant prior to patient contact. This will eliminate the possibility of cross-contamination occurring via containers, tubes, and dispensers.

Large, non-sterilizable items used in the operatory, such as impression material dispensing guns, articulators, face bows, water bath, silicone spray bottles, tooth shade, and mold guides are disinfected by wiping, spraying, or immersion with the appropriate disinfectant solution. ${ }^{7}$

All items leaving the clinic that are used in direct patient care or touched during patient care procedures that cannot be subjected to sterilization procedures are disinfected or placed in the phenol disinfection solution within a sealed plastic bag before departure. New latex gloves are worn for the disinfection procedures. ${ }^{3}$

\section{Disinfection of impressions:}

American Dental Association (ADA) guidelines state that impressions should be rinsed to remove saliva, blood and debris and then disinfected before being sent to the laboratory. When considering methods of disinfection for impressions, two factors are important: 1) the effect of the treatment on the dimensional stability and surface detail of the impression and 2) the deactivating effect of the impression material on the disinfecting solution, which could reduce the efficacy of the process. ${ }^{12}$

Polyvinylsiloxane, polysulfide, impression compound, and Zinc oxide eugenol (ZOE) impression materials are thoroughly rinsed under water and immersed in a $5.25 \%$ sodium hypochlorite solution for 10 minutes (9-12). Alginate and polyether impressions are rinsed under water, sprayed with a $5.25 \%$ sodium hypochlorite solution and sealed in a plastic bag for at least 10 minutes. 2\% glutaraldehyde did not affect the accuracy and dimensional stability of polyether and polyvinyl siloxane impression materials after immersion for 30 or 60 minutes. ${ }^{13}$ Twenty minute immersion in 2\% ID 210 solution (Durr Dental, Bissingen, Germany) has no adverse effects on the dimensional stability or surface detail reproduction of rigid material such as an impression compound, impression plaster, and zinc oxide-eugenol impression material. ${ }^{14}$

\section{Impression trays:}
Aluminum
- Heat sterilize via autoclave, chemical vapor or dry heat; ethylene oxide sterilization.
Chrome-plated
- Heat sterilize via autoclave,
chemical vapor or dry heat;
ethylene oxide sterilization.
Custom acrylic resin - Discard after intraoral use in a patient; disinfect with tuberculocidal hospital disinfectant for reuse during the same patient's next visit.
Plastic - should be discarded ${ }^{1}$

\section{Disinfection of wax bites/ rims, bite registrations:}

Wax, ZOE, and resin centric relation records are rinsed under water and sprayed with a $5.25 \%$ sodium hypochlorite solution and placed in a plastic bag for 10minutes. ${ }^{15}$

\section{Disinfection of casts:}

Stone casts are the most difficult item to be disinfected without causing any much damage. Casts requiring disinfection are sprayed with a $5.25 \%$ sodium hypochlorite solution and allowed to sit for at least 10 minutes. $^{3}$

\section{Disinfection of dental prostheses:}

Complete dentures and provisional restorations that leave the operatory are immersed in a $5.25 \%$ sodium hypochlorite solution for 10 minutes. Removable partial dentures with metal bases are sprayed with $2 \%$ gluteraldehyde solution and held 
in a plastic bag for 10 minutes. $^{3}$

\section{Laboratory disinfection:}

The dental laboratory becomes the second line of infection control barriers that protect the patients, residents, assistants, and faculty. All prostheses that enter and leave the laboratory are disinfected. All prostheses entering the laboratory are scrubbed with disinfectant solution. Those leaving the laboratory are immersed in a $5.25 \%$ sodium hypochlorite solution for a minimum of 10 minutes. Laboratory countertops are cleaned and wi ped with disinfectant solution at the end of each day. Individually packaged chemiclaved laboratory burs are available in the laboratory. After the desired procedure is accomplished, the laboratory bur is cleaned and placed in a new bag for sterilization. The burs are used for one patient only and then re sterilized. For polishing the lathe, when the technician should use individually packaged sterile polishing wheels, designated for use with pumice. The addition of an antiseptic product that contained Octenidine as active agent to conventional pumice reduced the number of microorganisms by $99.999 \%$. The mix of steribim with water reduced the number of bacteria by $99 \%$. The wheel is wet with water to soften it before use. ${ }^{16}$ If prosthesis becomes contaminated during laboratory procedures, it is disinfected and the laboratory procedure continued.

Final polish is accomplished using a sterile wheel with non contaminated acryluster. The acryluster is applied to the sterile wheel once before polishing to eliminate cross-contamination. Cleanup involves disposal of the plastic container and the contaminated pumice. Wheels are removed, rinsed under water, and bagged for autoclaving. Before returning to the main clinic, all items arc disinfected by immersion or spray and placed in a Lock-Tight bag. All information regarding disinfection procedures performed on Prosthodontic items sent to an outside laboratory is clearly written on the prescription form and the plastic bag. All items received from a laboratory are treated as contaminated unless the resident is informed otherwise by the dental laboratory. ${ }^{3}$

\section{Conclusion:}

The increased awareness of the dangers of cross contamination with hepatitis B virus (HBV) and HIV during dental procedures is having a growing impact on attitudes toward infection control in the dental clinic and laboratory. Lack of I nfection
Control is life-threatening for both the patient and the Dental Professional and requires more efforts. Formal programs in Infection Control and Safety must be developed and strictly followed by the entire dental health care professional. Many Countries in the world have strong guidelines and recommendations for dental safety. In a country like India, the concept is new and needs to be advocated on the highest priority.

\section{References:}

1. Vidya S Bhat, Mallika S Shetty, Kamalakanth K. Shenoy Infection control in prosthodontic laboratory. The journal of Indian Prosthodontic Society 2007; 7(2):62-5

2. Anil Kohli, Raghunath Puttaiah. Infection control and occupational safety recommendations for oral health professionals in India. 2007

3. Neeeraj Rampal, Salil Pawah, Pankaj Kaushik. Infection Control in Prosthodontics. J Oral Health Comm Dent 2010; 4(1):7-11

4. Naveen $B H$, Kashinath $K R$, Jagdeesh $K N$, Rashmi $B$ Mandokar. Infection control in prosthodontics. J Dent Sci Res 2011; 2(1):93-107.

5. Infection Control in Dentistry; Dental Clinics of North America 1996; 40(2):114-8.

6. Robert M Brandt, J ames P Cofey. Infection Control in a Prosthodontic residency program. J Prosthodont 1993; 2:55-

7. Siddharth Phull, Arvind Arora, Yashendra. Sterilization and Disinfection In Prosthodontics. Ind J Dent Sci 2014; 6(4):112-6.

8. ClareConnor. Cross- contamination control in prosthodontic practice. Int J Prosthodont 1991; 4:337-44.

9. Council on dental materials, instruments, and equipment, council on dental practice, council on dental therapeutics. "Infection control recommendations for the dental office and the laboratory". J Am Dent Assoc 1998; 116:241-8.

10. Technical Bulletin. Disinfection and Sterilization of dental instruments and materials. TB MED 1995 pg 266.

11. Hiolinari J A, Mdinari GE. Is mouth rinsing before dental procedures worthwhile? J Am Dent Assoc 1992; 123:75-80.

12. McNeill MR, Coulter WA, Hussey DL. Disinfection of irreversible Hydrocolloid impressions: A comparativestudy. Int J Prosthodont 1992; 5:563-7.

13. Maria del Pilar Rios et al .Effects of chemical disinfectant solutions on the stability and accuracy of the dental impression complex. J Prosthet Dent 1996; 76:356-62.

14. Fong. PG, Walter J D. The effects of an immersion disinfection regime on rigid impression materials. Int J Prosthodont 1990; 3:522 -7.

15. Naylor WP. Prosthodontic items of interest. Int J Prosthodont. 1992; 5:188-9.

16. J urgen Setz, Peter Heeg. "Disinfection of Pumice". J Prosthet Dent, 1996; 76:448-50. 